\title{
BMJ Open Body mass index is associated with the maternal lines but height is heritable across family lines in the Lifeways Cross-Generation Cohort Study
}

\author{
Gabrielle E Kelly, ${ }^{1}$ Celine Murrin, ${ }^{2}$ Karien Viljoen, ${ }^{2}$ John O'Brien, ${ }^{2}$ Cecily Kelleher ${ }^{2}$
}

To cite: Kelly GE, Murrin C, Viljoen $\mathrm{K}$, et al. Body mass index is associated with the maternal lines but height is heritable across family lines in the Lifeways CrossGeneration Cohort Study. BMJ Open 2014;4:e005732. doi:10.1136/bmjopen-2014005732

- Prepublication history for this paper is available online. To view these files please visit the journal online (http://dx.doi.org/10.1136/ bmjopen-2014-005732).

Received 20 May 2014 Revised 27 November 2014 Accepted 28 November 2014

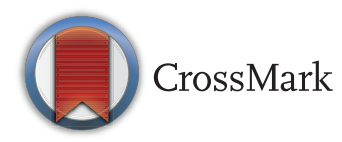

${ }^{1}$ School of Mathematical Sciences, University College, Dublin, Ireland

${ }^{2}$ School of Public Health, Physiotherapy and Population Science, University College Dublin, Dublin, Ireland

Correspondence to Dr Gabrielle E Kelly; gabrielle.kelly@ucd.ie

\section{ABSTRACT}

Objectives: Overweight and obesity is a problem in children in particular and determining pathways of transmission is important in prevention. We aimed to examine associations for body mass index (BMI) across three generations of the same families. Participants: Members of 556 families in the Lifeways Cross-Generation Cohort Study 2001-2014.

Setting: Community-based study with linkage to health records in the Republic of Ireland.

Methods: Employing a novel mixed-method approach which adjusts for age and familial group, BMI correlations were estimated at three ages of the index child, that is, at birth and at ages 5 and 9 . Height was also examined for comparative purposes.

Results: Correlation of offspring's BMI with that of the mother increased with age (correlation coefficient 0.15 increasing to $0.28, p$ value $<0.001$ in all cases) while no consistent pattern was seen with offspring and fathers.

There was an association also with each parent and their own mother. Offspring's BMI was correlated to a lesser extent with that of the maternal grandmother while for girls only there was an association with that of the paternal grandmother at ages 0 and 5 (correlation coefficients $0.25,0.28$, p values $0.02,0.01$,

respectively). In contrast, height of the child was strongly associated with those of all family members at age 5 , but at birth and at age 9 only there was an association with those of the parents and the paternal grandfather. Correlation of offspring's height with those of the mother and father increased with age.

Conclusions: The results suggest that BMI is predominantly associated with the maternal line, possibly either with intrauterine development, or inherited through the $\mathrm{X}$ chromosome, or both, while height is a more complex trait with genetic influences of the parents and that of the paternal grandfather predominating.

\section{INTRODUCTION}

Increasing body mass index (BMI) and obesity levels in current populations are a source of concern for public health policy in many countries. There is significant interest

\section{Strengths and limitations of this study}

- This is one of the few studies to examine association between grandparents' characteristics and grandchildren's growth across seven lineages and at three time points.

- The results of this study are novel, suggesting that body mass index is predominantly associated with maternal pathways, whether through intrauterine development or inherited through the $\mathrm{X}$ chromosome or both.

- The statistical analysis is novel, using mixedmodel techniques that enable all the data to be utilised including incomplete families.

- A limitation is the relatively small numbers of respondents with differential response rates at each sweep, particularly when children averaged 9 years of age.

- A further limitation is the possibility that deceased grandparents would have different patterns of association with their grandchildren than those living.

in what influences weight gain over the life course and the degree to which risk of overweight or obesity is transmitted across generations of families. ${ }^{1-3}$ From studies that have examined the heritability of $\mathrm{BMI}^{4}{ }^{5}$ it is clear that BMI does have a heritable component. However, the majority of family studies of BMI examine relationships between two generations only and are not adjusted for cohort effects. Studies in which BMI of children is documented at repeated times show strong tracking patterns with age,${ }^{6-9}$ but this has not been reported in relation to family lineages including grandparents.

There are very few human studies which include three generations of family members and which also collect anthropometric data or study heritability patterns. The Genetics of Pre-eclampsia (GOPEC) consortium studied patterns of inheritance across three generations in relation to risk of pre-eclampsia. ${ }^{10}$ 
A US study, employing self-reported grandparental data, looked at familial associations for childhood overweight. ${ }^{11}$ In Hong Kong, an economy in epidemiological transition, grandparental and parental education in relation to childhood weight was studied, the parental influence being stronger. ${ }^{12} \mathrm{~A}$ small number of studies have been reported which examine grandparental morbidity and mortality data in relation to infant birth weight and growth patterns. ${ }^{13-16}$ Most recently, data from the Overkalix study in Sweden, which relates famine experience decades ago with current grandchildren's cardiovascular disease outcomes, suggest that the paternal grandmother's (PGM) exposure to famine-like conditions in childhood was associated with an increased likelihood of cardiovascular disease in her adult granddaughter, whereas the mortality association was limited to grandsons for the paternal grandfather (PGF) ${ }^{17} 18$ The maternal grandmother (MGM) may be particularly significant, because she supplies the ovum through the mother to her grandchild, as well as her nurturing role to the mother and grandchild. ${ }^{1}{ }^{19}$ Both grandmothers provide an intrauterine environment for the respective parents of any index grandchild. Anthropological studies also suggest the particular importance of the MGM for children's development. ${ }^{20}$

The Lifeways Cross-Generation Cohort Study was established in 2001 with the a priori purpose of assessing associations across generations and between family members. ${ }^{21-25}$ We have shown in several previous analyses that there is a stronger association with children's outcomes along the maternal than the paternal line. ${ }^{23-25} \mathrm{In}$ the present study, we analyse patterns in BMI and height at three ages of the index child, employing primarily examination rather than self-reported data for adults. Our purpose was to assess if there are any similarities in BMI patterns within families and whether similarities are constant over the three time points and across generations. Height is also examined for comparative purposes.

\section{METHODS}

The data form part of the Lifeways Cross-Generation Cohort Study, established in 2001 and followed up through to 2013. The methodology has been described elsewhere and a number of reports with this data set have been published previously. ${ }^{21}{ }^{22}{ }^{26}$ Briefly, mothers were recruited at the antenatal booking visit initially and, in addition to their infant, were asked to recruit if possible their partner and at least one living grandparent. Only biological (grand)parents were included in the sample. Height and weight were collected in participants either through self-report or measurement at various sweeps (see table 1). For this analysis, we employ only measured data in the child, for example, weight and length at birth, weight and height at ages 5 and 9, measured weight and height of mother (when the child was aged 5) and grandparents (at baseline) and a mixture of measured and self-reported data for the fathers. The most complete data were available for the latter at these time points. There were 420 fathers with height and weight recorded when the child was aged 5 , but most of these were based on partners' self-report and only 77 were measured. There was a systematic and statistically significant difference in the height of the two groups of fathers-those measured were $175.8 \mathrm{~cm}$ tall on average and those reported were significantly taller at $178.7 \mathrm{~cm}$.

In order to address difficulties with heritability interpretation, we have employed a mixed-model analysis that uses fixed and random effects. ${ }^{27}$ The family component of variance is partitioned into variances of and correlations between family members. The model allows all data from incomplete families to be used. A linear mixed-model analysis is adopted. Each individual has a family id and within a family individuals are also numbered according to the group to which they belong: child $=1$, mother $=2$, father $=3$, MGM $=4$, maternal grandfather $(\mathrm{MGF})=5, \mathrm{PGM}=6$ and $\mathrm{PGF}=7$. The unit in the model is the family member. The mixed model includes group, age and group $\mathrm{X}$ age of the family member as fixed effects and a random family effect with an unstructured correlation matrix. Note: in the case of the child, age represents the exact age when measurements were made. Estimates of this correlation matrix are obtained providing estimates of correlations between the different groups, that is, child with mother, child with father and

\begin{tabular}{|c|c|c|c|c|c|c|c|}
\hline & Child & Mother & Father & MGM & MGF & PGM & PGF \\
\hline \multicolumn{8}{|l|}{ Baseline (N) } \\
\hline Self-reported & - & 923 & 297 & 237 & 138 & 135 & 88 \\
\hline Measured & 925 & - & - & 369 & 225 & 223 & 142 \\
\hline \multicolumn{8}{|l|}{ Year $5(\mathrm{~N})$} \\
\hline Self-reported & - & - & 420 & - & - & - & - \\
\hline Measured & 568 & 547 & 77 & - & - & - & - \\
\hline \multicolumn{8}{|l|}{ Year $9(\mathrm{~N})$} \\
\hline Self-reported & - & - & - & - & - & - & - \\
\hline Measured & 298 & 268 & 5 & 53 & 34 & 29 & 25 \\
\hline
\end{tabular}


so on, together with $\mathrm{p}$ values. These correlations measure the degree of association between the phenotypic values. The $p$ value of each correlation (or equivalently the SE of the correlation) is adjusted for the estimation of the other correlation coefficients and the fixed effects. The fixed effects are chosen to account for different mean levels of BMI for the sexes and for different generations. The maternal and paternal grandparents had separate fixed effects, that is, a different effect for the MGM than the PGM and a different effect for the MGF than the PGF as the populations were not balanced. The estimates are examined for patterns by sex and by generation across families so that possible causes may be inferred. This is carried out at each age point of the index child—at birth and at ages 5 and 9 .

In an analysis of change between the different ages, differences in BMI for different age groups are calculated and regressed on the BMI of each of the other family members in turn. The baseline BMI at the younger age is included as a covariate to adjust for regression towards the mean. ${ }^{28}$ In this analysis, it can be argued that effects on BMI common to both ages are cancelled and what remains are differential genetic effects, intrauterine effects and possibly environmental effects. A similar analysis of change is conducted for height. In what follows, population correlations are denoted by $r$ and estimates by $\hat{r}$. $p$ Values are denoted by $p$, and $p$ values less than 0.05 are regarded as statistically significant.

\section{RESULTS}

Descriptive statistics are displayed in table 2 for children at each age point and for each of the adult lineage groups.

\section{BMI}

Table 3 displays raw BMI correlations for the index child with family members together with the sample size.

Estimated BMI correlations, employing the mixed models, and adjusting for age, are shown at each time point for the children and across generations are then displayed in table 4.

\section{BMI-child age 0}

In the nuclear family, the correlation between the child and the mother was highly significant (table 4). When examined by gender, girls were only weakly correlated with the mother, but with boys the correlation was much stronger. These data have a few girls whose mothers have a very high BMI and these values appear to dilute the correlation between girls and mother. For boys, the correlation with the MGM was significant. The PGM was significantly correlated with girls, but not boys, at age 0 . The relationships with grandfathers were not significant (table 4).

\section{BMI—child age 5}

There was a strong correlation between the child and the mother, similar to that at age 0 (table 4 ). The

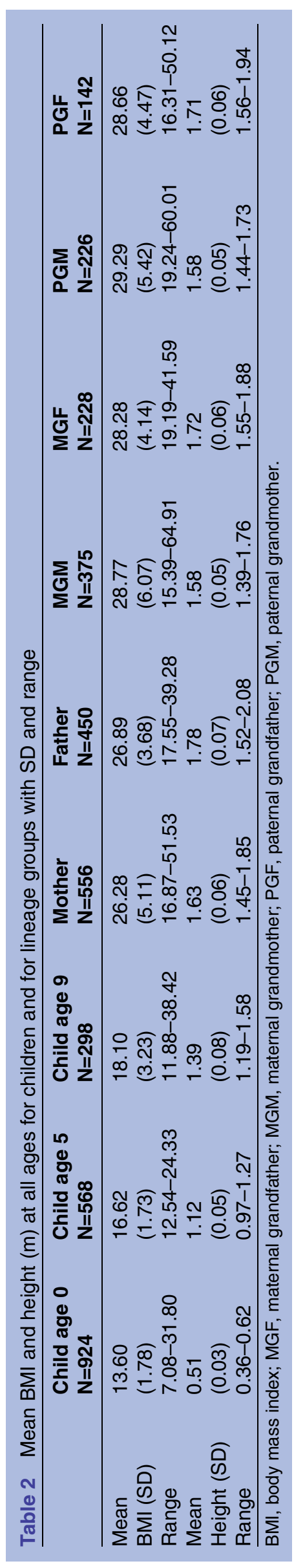


Table 3 Raw BMI correlations between child at ages 0,5 and 9 years and family members, with sample size (N) for each pair

\begin{tabular}{|c|c|c|c|c|c|c|c|}
\hline Group & Child & Mother & Father & MGM & MGF & PGM & PGF \\
\hline Child's age 0 & 1.000 & 0.139 & 0.054 & 0.113 & 0.063 & 0.093 & 0.054 \\
\hline$p$ Value & & $0.002^{*}$ & 0.277 & $0.043^{*}$ & 0.376 & 0.197 & 0.548 \\
\hline $\mathrm{N}$ & & 494 & 402 & 321 & 201 & 196 & 125 \\
\hline Child's age 5 & & 0.156 & 0.161 & 0.148 & 0.115 & 0.094 & 0.020 \\
\hline p Value & & $<0.001^{*}$ & $0.002^{*}$ & $0.029^{*}$ & 0.191 & 0.262 & 0.849 \\
\hline $\mathrm{N}$ & & 540 & 379 & 217 & 132 & 144 & 91 \\
\hline Child's age 9 & & 0.242 & 0.061 & 0.280 & 0.244 & 0.044 & 0.050 \\
\hline$p$ Value & & $<0.001^{*}$ & 0.369 & $0.001^{*}$ & $0.024^{\star}$ & 0.681 & 0.722 \\
\hline $\mathrm{N}$ & & 242 & 218 & 128 & 85 & 89 & 53 \\
\hline
\end{tabular}

*Significant associations, mainly in the maternal line.

BMI, body mass index; MGF, maternal grandfather; MGM, maternal grandmother; PGF, paternal grandfather; PGM, paternal grandmother.

corresponding correlation between the child and the father was also significant overall. The child's BMI was also correlated with the MGM. This was then carried out separately for boys and girls. Girls were correlated with fathers but not mothers and were also correlated with the MGM and PGM. Boys were correlated with mothers but not fathers (table 4).
BMI-child age 9

There were 298 children measured starting at age 9, with recruitment conducted over a 13-month period (mean age 9.85 years, $\quad \mathrm{SD}=0.29, \quad$ minimum $=9.2$, maximum $=10.89$ ). There was again a strong correlation of the child with the mother, this time being similar for boys and girls (table 4). There was also a correlation

Table 4 BMI correlations from a mixed model between the child at ages 0,5 and 9 years and family members

\begin{tabular}{|c|c|c|c|c|c|c|c|}
\hline Group & Child & Mother & Father & MGM & MGF & PGM & PGF \\
\hline Child's age 0 & 1.000 & 0.147 & 0.058 & 0.141 & 0.094 & 0.157 & 0.062 \\
\hline p Value & & $0.001^{*}$ & 0.246 & $0.031^{*}$ & 0.286 & 0.058 & 0.360 \\
\hline Child's age 5 & & 0.150 & 0.163 & 0.138 & 0.113 & 0.112 & 0.015 \\
\hline p Value & & $0.0007^{*}$ & $0.002^{*}$ & $0.024^{*}$ & 0.200 & 0.145 & 0.891 \\
\hline Child's age 9 & & 0.279 & 0.066 & 0.328 & 0.231 & 0.114 & -0.041 \\
\hline p Value & & $<0.0001^{*}$ & 0.352 & $<0.001^{\star}$ & $0.033^{*}$ & 0.334 & 0.797 \\
\hline Mother & & 1.000 & 0.094 & 0.245 & 0.070 & -0.010 & 0.004 \\
\hline$p$ Value & & & 0.084 & $<0.001^{*}$ & 0.477 & 0.892 & 0.967 \\
\hline Father & & & 1.000 & -0.094 & -0.131 & 0.255 & 0.072 \\
\hline p Value & & & & 0.185 & 0.109 & $0.006^{*}$ & 0.589 \\
\hline MGM & & & & 1.000 & 0.140 & -0.009 & -0.018 \\
\hline $\mathrm{p}$ Value & & & & & $0.047^{*}$ & 0.917 & 0.895 \\
\hline MGF & & & & & 1.0000 & -0.139 & -0.116 \\
\hline p Value & & & & & & 0.237 & 0.388 \\
\hline PGM & & & & & & 1.000 & 0.277 \\
\hline p Value & & & & & & & $0.004^{*}$ \\
\hline PGF & & & & & & & 1.000 \\
\hline \multicolumn{8}{|c|}{ BMI correlations between girls and boys at ages 0,5 and 9 years and family members } \\
\hline Girl's age 0 & - & 0.112 & 0.056 & 0.093 & 0.025 & 0.247 & 0.034 \\
\hline p Value & & 0.085 & 0.406 & 0.197 & 0.825 & $0.016^{*}$ & 0.788 \\
\hline Boy's age 0 & - & 0.169 & 0.054 & 0.336 & 0.184 & 0.049 & 0.087 \\
\hline p Value & & $0.005^{*}$ & 0.458 & $0.003^{*}$ & 0.127 & 0.673 & 0.323 \\
\hline Girl's age 5 & - & 0.063 & 0.175 & 0.133 & 0.132 & 0.277 & 0.140 \\
\hline p Value & & 0.304 & $0.013^{*}$ & 0.064 & 0.270 & $0.012^{*}$ & 0.254 \\
\hline Boy's age 5 & - & 0.230 & 0.124 & 0.172 & 0.049 & -0.041 & -0.224 \\
\hline $\mathrm{p}$ Value & & $0.0002^{*}$ & 0.107 & 0.114 & 0.704 & 0.698 & 0.265 \\
\hline Girl's age 9 & - & 0.248 & 0.019 & 0.262 & 0.228 & 0.018 & -0.089 \\
\hline $\mathrm{p}$ Value & & $0.012^{*}$ & 0.825 & $0.019^{*}$ & 0.134 & 0.914 & 0.624 \\
\hline Boy's age 9 & - & 0.258 & 0.181 & 0.516 & 0.321 & 0.147 & 0.538 \\
\hline p Value & & $0.012^{*}$ & 0.077 & $<0.0001^{*}$ & $0.006^{*}$ & 0.303 & $0.0001^{*}$ \\
\hline
\end{tabular}

*Significant findings.

BMI, body mass index; MGF, maternal grandfather; MGM, maternal grandmother; PGF, paternal grandfather; PGM, paternal grandmother. 
with the MGM for both boys and girls. Boys were also strongly correlated with the PGF at the age of 9 only. The size of the correlation between the child and the mother at this age was similar to that between the mother and the MGM and the father and the PGM.

\section{Changes in BMI with age}

In an analysis of change from birth to 5 years, the weight difference of the child was calculated (age 5-0) and regressed on the other family members' weight. The initial weight of the child was also included in the regression to adjust for regression towards the mean. A similar analysis was undertaken for BMI difference in the child. For girls, there was a significant change with the BMI of the father, $\mathrm{p}=0.010$, and a borderline significant change associated with the BMI of the PGM, $\mathrm{p}=0.066$, but no association with other family members. For boys, there was a positive change associated with the BMI of the mother, $\mathrm{p}=0.002$, but no association with other family members. In the analysis of change from age 5 to 9 (age 9-5), BMI change in girls was associated with the BMI of the mother, $\mathrm{p}=0.008$. BMI change in boys was associated (with borderline significance) with the PGF, $\mathrm{p}=0.061$. In general, BMI correlations of the child with the mother and MGM increased with age.

\section{Other familial associations for BMI}

The mother's BMI was highly significantly correlated with that of her own mother $\mathrm{p}<0.001)$. The same was seen for the father and his mother $(p=0.008)$. Both the maternal and paternal grandparental couples had significant BMI associations $(\mathrm{p}=0.033$ and $\mathrm{p}=0.013$, respectively). The correlations between the mother and the MGF and the father and his father, the PGF, were not statistically significant.

\section{Height}

The estimated height correlations at each age and across generations are displayed in (table 5).

\section{Height—child age 0}

The child's height/length was correlated with that of its mother and father and not with that of the other family members (table 5). Correlations in the nuclear family were stronger for the girls and there was a borderline significant association of girls with MGM.

Table 5 Height correlations from a mixed model between the child at ages 0,5 and 9 years and family members

\begin{tabular}{|c|c|c|c|c|c|c|c|}
\hline \multicolumn{8}{|c|}{ Height correlations between girls and boys at ages 0,5 and 9 years and family members } \\
\hline Group & Child & Mother & Father & MGM & MGF & PGM & PGF \\
\hline Child's age 0 & 1.000 & 0.133 & 0.196 & 0.061 & 0.036 & 0.105 & 0.079 \\
\hline p Value & & $0.002^{*}$ & $<0.0001^{*}$ & 0.277 & 0.624 & 0.157 & 0.309 \\
\hline Child's age 5 & & 0.386 & 0.363 & 0.182 & 0.191 & 0.247 & 0.424 \\
\hline p Value & & $<0.0001^{\star}$ & $<0.0001^{*}$ & $0.003^{*}$ & $0.014^{\star}$ & $0.001^{*}$ & $<0.0001^{*}$ \\
\hline Child's age 9 & & 0.412 & 0.388 & 0.133 & 0.132 & 0.225 & 0.425 \\
\hline p Value & & $<0.0001^{\star}$ & $<0.0001^{*}$ & 0.081 & 0.129 & $0.022^{*}$ & $0.0003^{*}$ \\
\hline Mother & & 1.000 & 0.146 & 0.420 & 0.441 & 0.077 & 0.001 \\
\hline$p$ Value & & & $0.004^{\star}$ & $<0.0001^{*}$ & $<0.0001^{\star}$ & 0.347 & 0.993 \\
\hline Father & & & 1.000 & 0.148 & 0.011 & 0.567 & 0.506 \\
\hline$p$ Value & & & & $0.027^{\star}$ & 0.893 & $<0.0001^{\star}$ & $<0.001^{\star}$ \\
\hline MGM & & & & 1.000 & 0.370 & 0.093 & -0.101 \\
\hline$p$ Value & & & & & $<0.0001^{\star}$ & 0.244 & 0.272 \\
\hline MGF & & & & & 1.000 & 0.076 & 0.040 \\
\hline p Value & & & & & & 0.485 & 0.733 \\
\hline PGM & & & & & & 1.000 & 0.351 \\
\hline$p$ Value & & & & & & & $<0.0001^{*}$ \\
\hline PGF & & & & & & & 1.000 \\
\hline Girl's age 0 & - & 0.175 & 0.253 & 0.128 & 0.115 & 0.047 & 0.257 \\
\hline p Value & & $0.003^{*}$ & $0.0001^{*}$ & 0.108 & 0.243 & 0.652 & 0.034 \\
\hline Boy's age 0 & - & 0.090 & 0.155 & -0.018 & -0.037 & 0.133 & 0.003 \\
\hline p Value & & 0.125 & $0.027^{\star}$ & 0.816 & 0.735 & 0.206 & 0.974 \\
\hline Girl's age 5 & - & 0.401 & 0.334 & 0.170 & 0.148 & 0.223 & 0.394 \\
\hline$p$ Value & & $<0.0001^{\star}$ & $<0.0001^{*}$ & $0.031^{*}$ & 0.122 & $0.020^{\star}$ & $0.0005^{\star}$ \\
\hline Boy's age 5 & - & 0.378 & 0.404 & 0.179 & 0.280 & 0.255 & 0.423 \\
\hline p Value & & $<0.0001^{*}$ & $<0.0001^{*}$ & $0.036^{\star}$ & $0.011^{*}$ & $0.015^{\star}$ & $0.005^{\star}$ \\
\hline Girl's age 9 & - & 0.445 & 0.340 & 0.111 & 0.198 & 0.136 & 0.472 \\
\hline$p$ Value & & $<0.0001^{\star}$ & $<0.0001^{*}$ & 0.236 & 0.058 & 0.335 & $0.002^{*}$ \\
\hline Boy's age 9 & - & 0.382 & 0.445 & 0.096 & 0.048 & 0.303 & 0.482 \\
\hline p Value & & $<0.0001^{*}$ & $<0.0001^{*}$ & 0.409 & 0.740 & $0.016^{\star}$ & $0.003^{*}$ \\
\hline
\end{tabular}

*Significant findings.

MGF, maternal grandfather; MGM, maternal grandmother; PGF, paternal grandfather; PGM, paternal grandmother. 


\section{Height—child age 5}

This correlation in the nuclear family became stronger at age 5 . The height of the child was strongly correlated with that of the mother and father, being similar for boys and girls. The mother was correlated with the MGM and with the MGF, while the father was also correlated with his mother and father. The height of the child was correlated with the height of all family members including all four grandparents, with the strongest correlations being with the parents and the PGF. The results for boys and girls were similar (table 5).

\section{Height—child age 9}

As at age 5 , the child's height at age 9 was strongly correlated with that of the mother and father and PGF. This was similar for boys and girls (table 5). However, the girl's height was more strongly correlated with that of the mother than father. The size of the correlations, between the child and each parent at this age, was a little lower than those between the mother and her parents and the father and his parents.

\section{Changes in height with age}

This was carried out separately for boys and girls. For girls, change in height at age 5-0 was correlated with the height of the mother, $\mathrm{p}<0.0001$, and father, $\mathrm{p}=0.0003$. For boys, change in height was correlated with the height of the mother, $\mathrm{p}<0.0001$, and father, $\mathrm{p}<0.0001$, borderline significance with MGM $\mathrm{p}=0.080$, and with PGF $\mathrm{p}=0.009$. For girls, change in height at age 9-5 was correlated with the height of the mother, $\mathrm{p}=0.008$, and height of the father, $\mathrm{p}=0.031$. For boys, the same change was only correlated with the height of the father, $\mathrm{p}=0.047$. In general, height correlations of the child with each parent increased with age.

\section{DISCUSSION}

This highly novel cohort study is one of very few human studies in the literature with examination data across three generations and both lineages which can be linked to children's growth patterns at three different time points. ${ }^{22}$ To the best of our knowledge, there are no other reported human cross-generational data sets in the literature with four grandparental lines and three time points of measured BMI, so this is an original contribution to the scientific literature. This is also highly topical currently. Wells, in a recent commentary, indicates the need for such cross-generational grandparental data to understand more fully the influence of maternal and paternal lineages on growth and development. ${ }^{19}$

In a previous study employing primarily self-reported data, we showed that BMI appeared to be strongly familial in the maternal line,${ }^{23}$ and we have shown that familial dietary patterns are also stronger in the maternal line. ${ }^{24} 25$ The present analysis of BMI has extended this to include both birth weight and data when the children were aged 9 years and shows this strong maternal pattern consistently for children while height, by comparison, is heritable across lineages. Similar patterns were seen across the generations for BMI and height. In our original publication, we used examination data at one time point only for the children when they were aged 5; we now report examination data at three separate time points, including a completely new sweep of data when children were aged 9 .

It cannot be assumed that in a growing child these relationships with family members would remain consistently the same, in that environmental factors would come more into play as the child grows up. ${ }^{29}$ As children grow older in this study, the BMI relationship strengthens, presumably because of shared dietary environments, and to reinforce this, both grandparent couples also have significantly correlated BMI relationships. This is therefore a novel analysis and a considerable expansion on the previous one. In the original paper, we used only self-reported height and weight data for all adults, whereas this time we are reporting examination data for mothers and grandparents. Not alone is this now more robust, but also it is a substantial scientific addition using novel data to build on our previous observation. In this cohort, we have collected detailed information on social and environmental influences on the child's development and in a number of other publications address this question, including cultural and familial influences. We have, for instance, established dietary associations between nuclear family members and have shown that maternal pregnancy diet is associated with a number of outcomes, including child's risk of asthma, overweight and obesity. ${ }^{22}$

There are powerful environmental influences at play in familial studies. A report of the Young Finns Study followed offspring in relation to parental BMI from 3 to 18 years and later again when children were 24-39 years old. Maternal BMI was much more strongly associated with offspring BMI than that of father initially, but no differences in parental associations were seen when the offspring became adults. ${ }^{29}$

We approached this analysis looking for consistency and coherence of association as well as magnitude and statistical significance and include also the height analysis, which has the same numbers of respondents, to show that the absence of an association for BMI by comparison is not simply due to a power problem. While there are, for example, more mothers than fathers, there are relatively less grandparents, and yet both grandmothers do show statistically significant associations. Ponderal index is the clinical measure normally used at birth. However, we are not seeking to report or measure adiposity in itself in this analysis; for comparator purposes, we report BMI at the three time points in order to compare like with like both (1) in relation to the child over time and (2) in relation to the adults. Cole $e t a l,{ }^{30}$ for instance, concluded that ponderal index was not appropriate for measuring intrauterine malnutrition. 
There were no correlations between BMI of the child of either sex at ages 0 and 5 with maternal or PGFs, so this evidence suggests that transmission of BMI is not primarily genetic. BMI of boys was correlated with that of the MGM at two points but was not correlated with that of the PGM. For the girls, there was a weak correlation with the MGM but a stronger correlation with the PGM at ages 0 and 5. The PGM transmits an X chromosome, which is the female sex chromosome, exclusively to her granddaughter, while girls on the maternal side may receive their $\mathrm{X}$ chromosome from either grandparent through their mother. The PGM does not transmit her X chromosome to the boys and the PGF does not transmit his $\mathrm{Y}$ chromosome to the girls. One of the highest $\mathrm{p}$ values for the girls (ie, the least significant correlation) was with the PGF, and the highest $p$ values for the boys (ie, the least significant correlation) was with the PGM. Thus, this suggests that BMI is not transmitted via mitochondrial DNA or, if so, only weakly. This leaves the intrauterine environment or genetic transmission on the sex chromosome with evidence suggesting the latter, since there are no correlations with the grandfathers or of boys with the PGM.

A recent study $^{17}$ found that female grandchildren have an increased risk of cardiovascular mortality if their PGM experienced a drastic change in food availability in their childhood. It indicated that X linked epigenetic inheritance via spermatozoa seemed to be plausible, with the transmission, limited to being through the father, possibly explained by the sex differences in the meiosis stage of cell reproduction. A similar explanation is plausible in this study for BMI.

We are not basing our conclusion that the maternal line is stronger solely on the fact that the mother-child correlations at age 5 are significant. We do so based on the facts that the overall maternal-child relationships are significant at all three time points, that there are correlations between all three mother-child pairs, for example, mother-child, MGM-mother and PGM-father, and that, in contrast to height, where both lineages show significant associations, the pattern for BMI is primarily the maternal lineage. Intrauterine transmission must be considered important as the maternal relationship is consistent at all time points and between each mother-child pair, for example, the mother and her children, the mother and her own mother and the father and his mother. While there have been conflicting reports in the literature with, for instance, the Avon Longitudinal Study of Parents and Children (ALSPAC) ${ }^{3}$ reporting equivalent relationships between the child's BMI and both parents, the Generation R study ${ }^{2}$ reports that the maternal influence is strongest. A large Norwegian study ${ }^{31}$ has recently reported largely similar father-offspring and mother-offspring associations in adults across cardiovascular risk factors. However, in 9 of the 12 variables studied, age-standardised correlations were of a higher magnitude between mother and offspring, significantly so for height, systolic blood pressure, total cholesterol and high-density lipoprotein cholesterol. As has been pointed out, ${ }^{19}$ the relationship between the MGM in particular, her daughter and grandchild represents a 100 years of nutritional flow, including intrauterine, genetic, mitochondrial and environmental nutritional pathways and these data illustrate this effect. Morton et $a l^{16}$ indicate that population strategies aimed at optimising size at birth require intergenerational considerations for social as well as biological reasons.

One key reason we conclude that intrauterine or $\mathrm{X}$-mediated influences are important is because the grandmothers of both lineages, who do not share their grandchildren's direct daily environment, are each exerting an association. Most studies do not have grandparental data from both lineages. The MGM could arguably have influenced her daughter's culinary and dietary habits and hence her grandchild's BMI, ${ }^{25}$ but the PGM is associated with the paternal granddaughter and not her paternal grandson. It is entirely plausible that this is biologically mediated, and not purely environmental, as we posit, and was also reported in the Overkalix study. ${ }^{17} 18$

In a meta-analysis of 26 family studies, ${ }^{5}$ BMI heritability estimates ranging from 0.24 to 0.81 were reported. Our correlation estimates (corresponding to half the heritability) of 0.25 between the mother and the MGM and 0.26 for the father and the PGM are consistent with these as is the value 0.28 for that of the child at age 9 with the mother. The analysis ${ }^{5}$ reported that heritability estimates rose by 0.012 /year throughout childhood (age $\leq 18$ years) but decreased by $-0.002 /$ year in adulthood. Our correlation estimates of 0.15 of the child at age 0 with the mother rising to 0.25 at age 9 and averaging at 0.25 in adulthood is consistent with this with the caveat that no change was seen between age 0 and 5 . Note that a similar pattern was not seen for offspring and fathers. Also note that, as in that analysis, ${ }^{5}$ we found no difference in BMI heritability estimates between men and women. In contrast to BMI, height correlation estimates between the offspring and the mother are quite similar to those between the offspring and the father for each of the three child ages and each generation. The estimates increased rapidly from age 0 to 5 and then at a slower rate, reaching maximum values in adulthood. The estimates are greater than those for BMI throughout.

Modern techniques for genetic analysis create opportunities for understanding the heritability of complex traits and risk for chronic diseases. ${ }^{27}{ }^{32}$ Height is one of the more complex genetically inherited traits because as many as 20 genes - if not more-interact to determine a child's height. Geneticists have found genes for height on the 7th, 8th and 20th chromosomes, as well as on the $\mathrm{X}$ chromosome. A recent report shows that combined common single-nucleotide polymorphisms explain a large proportion of the heritability for human height. ${ }^{33}$ What is under-researched to date is the degree to which the $\mathrm{X}$ chromosome might be contributing to human obesity. ${ }^{34}$ Unlike other authors, ${ }^{35}$ we did not find heritability for postnatal length to be higher for maternal height than for 
paternal height. In our analysis, it was found that the child's height was correlated with that of all family members at age 5, suggesting perhaps many genetic effects. Thus, the common estimate of heritability assuming additive genetic effects may not work for height. ${ }^{36}$ However, at ages 0 and 9 , height was primarily correlated in the nuclear family and similar correlations were observed for the parents with the grandparents. Interestingly, the height of the child continued at ages 5 and 9 to be strongly correlated with that of the PGF, not easily explainable by conventional genetic inheritance, though there may be a Y-related influence at play through the father, who himself is highly correlated with his father.

There was a systematic and statistically significant difference in the height of the two groups of fathersthose reported were significantly taller than those measured. This may be because reported data were exaggerated by the partner or because, for some reason, reported is a healthier group than measured height. For the small numbers of fathers we measured, there was a significantly lower height than in those we reported. However, the latter explanation is less likely since the two groups do not differ in weight or heights and weights of their partners-that is, the mother, or heights and lengths of child at age 0 . It is well known that male heights tend to be greater in reported than measured data. ${ }^{37}$ Our analysis suggests that it is unlikely that correlations were affected by this feature.

Probably the most familiar technique in estimating heritability is parent-offspring regression in which, for example, a trait's heritability can be estimated as the slope of the regression of offspring phenotype on midparent phenotype. It has been noted ${ }^{36}$ that if the sexes are not equal in phenotypic variance, then regression of daughters on fathers, for example, must be adjusted for the difference in variation. The adjusted regression is the correlation between the phenotypes. Twice this correlation is then defined to be the heritability. Thus, correlations between the phenotypes reported here can be taken to approximate half the heritability. In addition, adjustments for multiple testing were made in this model. Studies on children are likely to be overrepresentative of individuals from more recent birth years, but the separation of birth cohort and age effects on BMI correlation was possible in this study by including age-fixed and generation-fixed effects in the model. Age-genotype interactions are also modelled by the latter. Thus, correlation estimates obtained are comparable across cohorts and age groups.

Our data do have limitations, as they are based on a relatively small-scale cohort with differential response rates at each sweep and the numbers of measured children at age 9 was considerably lower than in the previous sweeps. We agree that caution is appropriate accordingly in data interpretation as the numbers at age 9 are smaller. In previous publications, we have reported on the representativeness of the participating mothers and children and find, as with many cohorts, that less affluent and younger mothers were less likely to continue to participate, but the baseline maternal BMI does not differ between responders and non-responders. ${ }^{22}$ Also, we only report statistically significant findings which by definition are sufficiently powered when the child is aged 9. There may be some self-selection bias in relation to participating grandparents, as clearly grandparents who were deceased could not participate. ${ }^{26} \mathrm{In}$ previous analyses, we have shown that the original index mothers were representative of the general population, ${ }^{22}$ and our findings were consistent across the three sweeps, so we do not think self-selection can be the main explanatory factor for our findings.

In conclusion, this novel cohort study shows clear familial associations across three generations for height in both lineages, but the BMI pattern is stronger in the maternal line.

Contributors The Lifeways study was designed and carried out by the Lifeways Steering Group of which CK is a founding member. CK conceived of the study and has overseen all sweeps and data outputs to date. CM and KV had respectively a major input into data collection and interpretation of 5 -year-old and 9-year-old child data. GEK analysed the data and led the drafting of the manuscript. JOB was responsible for data management and data integrity. All authors contributed to subsequent drafts and have read and approved the final manuscript.

Funding The Lifeways Cross-Generation Cohort Study has been supported in all sweeps since its establishment in 2001 by the Health Research Board of Ireland (grant numbers HRA_PHS/2010/13, R12052 and R13279).

\section{Competing interests None.}

Ethics approval The Lifeways Cross-Generation Study has received ethical approval for each stage. Approval for the 2011-2013 stage of the study was given by the University College Dublin Research Ethics Committee and St. Vincent's University Hospital Research Ethics Committee.

Provenance and peer review Not commissioned; externally peer reviewed.

Data sharing statement No additional data are available.

Open Access This is an Open Access article distributed in accordance with the Creative Commons Attribution Non Commercial (CC BY-NC 4.0) license, which permits others to distribute, remix, adapt, build upon this work noncommercially, and license their derivative works on different terms, provided the original work is properly cited and the use is non-commercial. See: http:// creativecommons.org/licenses/by-nc/4.0/

\section{REFERENCES}

1. Barker DJP. The developmental origins of chronic disease. Public Health 2012;126:189-95.

2. Durmus B, Arends LR, Ay L, et al. Parental anthropometrics, early growth and the risk of overweight in pre-school children: the Generation R Study. Pediatr Obes 2013;8:339-50.

3. Smith GD, Steer C, Leary $S$, et al. Is there an intrauterine influence on obesity? Evidence from parent child associations in the Avon Longitudinal Study of Parents and Children (ALSPAC). Arch Dis Child 2007;92:876-80.

4. Allison DB, Kaprio J, Korkeila M, et al. The heritability of body mass index among an international sample of monozygotic twins reared apart. Int J Obes Relat Metab Disord 1996;20:501-6.

5. Elks CE, den Hoed M, Zhao JH, et al. Variability in the heritability of body mass index: a systematic review and meta-regression. Front Endocrinol (Lausanne) 2012;3:29-34.

6. Mossberg HO. 40-year follow-up of overweight children. Lancet 1989;2:491-3.

7. Gulati AK, Kaplan DW, Daniels SR. Clinical tracking of severely obese children: a new growth chart. Pediatrics 2012;130:1136-40.

8. Miersch A, Vogel M, Gausche R, et al. Blood pressure tracking in children and adolescents. Pediatr Nephrol 2013;28:2351-9. 
9. Lo JC, Chandra M, Sinaiko A, et al. Severe obesity in children: prevalence, persistence and relation to hypertension. Int J Pediatr Endocrinol 2014;2014:3.

10. Genetics of Pre-eclampsia (GOPEC) consortium. Babies, pre-eclamptic mothers and grandparents: a three-generation phenotyping study. J Hypertens 2007;25:849-54.

11. Davis MM, McGonagle K, Schoeni RF, et al. Grandparental and parental obesity influences on childhood overweight: implications for primary care practice. J Am Board Fam Med 2008;21:549-54.

12. Kwok MK, Leung GM, Lam TH, et al. Grandparental education, parental education and child weight: evidence from Hong Kong's Children of 1997 birth cohort. Ann Epidemiol 2013:23:475-84

13. Manor O, Koupil I. Birth weight of infants and mortality in their parents and grandparents: the Uppsala Birth Cohort Study. Int $J$ Epidemiol 2010;39:1264-76.

14. Shrivastava A, Murrin C, O'Brien J, et al. Grandparental morbidity and mortality patterns are associated with infant birth weight in the Lifeways cross-generation cohort study 2001-2010. J Dev Orig Health Dis 2012;3:458-68.

15. Smith GC, Wood AM, White IR, et al. Birth weight and risk of cardiovascular disease in the maternal grandparents. Am J Epi 2010;171:736-44.

16. Morton SM, De Stavola BL, Leon DA. Intergenerational determinants of offspring size at birth: a life course and graphical analysis using the Aberdeen Children of the 1950s Study (ACONF). Int J Epidemiol 2014:43:749-59.

17. Bygren LO, Tinghög $\mathrm{P}$, Carstensen $\mathrm{J}$, et al. Change in paterna grandmothers' early food supply influenced cardiovascular mortality of the female grandchildren. BMC Genet 2014;15:12

18. Pembrey ME, Bygren LO, Kaati G, et al. Sex-specific, male-line transgenerational responses in humans. Eur J Hum Genet 2006:14:159-66.

19. Wells JC. Commentary: paternal and maternal influences on offspring phenotype: the same, only different. Int J Epidemiol 2014;43:772-4

20. Sear R, Mace R. Who keeps children alive? A review of the effects of kin on child survival. Evol Hum Behav 2008;29:1-18.

21. O'Mahony D, Fallon UB, Hannon F, et al. The Lifeways Cross-Generation Study: design, recruitment and data management considerations. Ir Med J 2007;100:Suppl 3-6.

22. Kelleher $\mathrm{CC}$, Viljoen $\mathrm{K}$, Khalil $\mathrm{H}$, et al. Longitudinal follow-up of the relationship between dietary intake and growth and development in the Lifeways cross-generation cohort study 2001-2013. Proc Nutr Soc 2013;3:1-14
23. Murrin CM, Kelly GE, Tremblay RE, et al. Body mass index and height over three generations: evidence from the Lifeways cross generational cohort study. BMC Public Health 2012;12:81-91.

24. Murrin CM, Shrivastava A, Kelleher CC. Maternal macronutrient intake during pregnancy and 5 years postpartum and associations with child weight status aged five. Eur J Clin Nutr 2013;67:670-9.

25. Shrivastava A, Murrin C, Sweeney MR, et al. Familial intergenerational and maternal aggregation patterns in nutrient intakes in the Lifeways Cross-Generation Cohort Study. Public Health Nutr 2013;16:1476-86.

26. Kelleher CC, Fallon UB, Fitzsimon N, et al. The risk factor profile of grandparents. Ir Med J 2007;100:Suppl 15-19.

27. Visscher PM, Hill WG, Wray NR. Heritability in the genomics eraconcepts and misconceptions. Nat Rev Genet 2008;9:255-66.

28. Galton F. Regression towards mediocrity in hereditary stature. $J$ Anthropol Inst 1886;15:246-63.

29. Kivimaki M, Lawlor DA, Davey Smith G, et al. Substantial intergenerational increases in body mass index are not explained by the fetal overnutrition hypothesis: the Cardiovascular Risk in Young Finns study. Am J Clin Nutr 2007;86:1509-14.

30. Cole TJ, Henson GL, Tremble JM, et al. Birthweight for length: ponderal index, body mass index or Benn index? Ann Hum Biol 1997:24:289-98.

31. Vik KL, Romundstad P, Carslake D, et al. Comparison of father-offspring and mother-offspring associations of cardiovascular risk factors: family linkage within the population-based HUNT Study, Norway. Int J Epidemiol 2014;43:760-71.

32. Manolio TA, Collins FS, Cox NJ, et al. Finding the missing heritability of complex diseases. Nature 2009;461:747-53.

33. Yang J, Benyamin B, McEvoy BP, et al. Common SNPs explain a large proportion of the heritability for human height. Nat Genet 2010;42:565-9.

34. Price RA, Li WD, Kilker R. An X-chromosome scan reveals a locus for fat distribution in chromosome region Xp21-22. Diabetes 2002;51:1989-91.

35. Mook-Kanamori DO, van Beijsterveldt CEM, Steegers EAP, et al. Heritability estimates of body size in fetal life and early childhood. PLoS One 2012;7:e39901.

36. Falconar D, Mackay T. Introduction to quantitative genetics. 4th edn Essex, England: Addison-Wesley Longman Ltd., 1996:165.

37. Shiely F, Perry IJ, Lutomskiy J, et al. Temporal trends in misclassification patterns of measured and self-report based body mass index categories-findings from three population surveys in Ireland. BMC Public Health 2010;10:560. 